\title{
Latent class analysis suggests four distinct classes of complementary medicine users among women with breast cancer
}

\author{
Garrett Strizich', Marilie D. Gammon², Judith S. Jacobson 1,3, Melanie Wall4, Page Abrahamson², \\ Patrick T. Bradshaw ${ }^{2,5}$, Mary Beth Terry ${ }^{1,3}$, Susan Teitelbaum ${ }^{6}$, Alfred I. Neugut ${ }^{1,3,7}$ and Heather Greenlee ${ }^{1,3,8^{*}}$
}

\begin{abstract}
Background: Breast cancer patients commonly report using $>1$ form of complementary and alternative medicine (CAM). However, few studies have attempted to analyze predictors and outcomes of multiple CAM modalities. We sought to group breast cancer patients by clusters of type and intensity of complementary and alternative medicine (CAM) use following diagnosis.

Methods: Detailed CAM use following breast cancer diagnosis was assessed in 2002-2003 among 764 female residents of Long Island, New York diagnosed with breast cancer in 1996-1997. Latent class analysis (LCA) was applied to CAM modalities while taking into account frequency and intensities.

Results: Four distinct latent classes of CAM use emerged: 1) "Low-dose supplement users" (40\%), who used only common nutritional supplements; 2) "Vitamin/mineral supplement users" (39\%), using an abundance of supplements in addition to other practices; 3) "Mind-body medicine users" (12\%), with near-universal use of supplements, mind-body medicine techniques, and massage; and 4) "Multi-modality high-dose users" (9\%), who were highly likely to use nearly all types of CAM. Predictors of membership in classes with substantial CAM use included younger age, more education, higher income, Jewish religion, ideal body mass index, higher fruit and vegetable intake, higher levels of physical activity, receipt of adjuvant chemotherapy, and prior use of oral contraceptives.

Conclusions: LCA identified important subgroups of breast cancer patients characterized by varying degrees of complementary therapy use. Further research should explore the reproducibility of these classes and investigate the association between latent class membership and breast cancer outcomes.
\end{abstract}

Keywords: Alternative medicine, Breast cancer, Latent class analysis, Epidemiology

\section{Background}

Complementary and alternative medicine (CAM) is generally defined to include all medical systems, practices and products that are not part of conventional medicine [1]. Individuals in many developed countries use CAM for both illness treatment and disease prevention [2]. CAM use is particularly common among breast cancer patients and survivors; in several samples more than

\footnotetext{
* Correspondence: hg2120@columbia.edu

'Department of Epidemiology, Mailman School of Public Health, Columbia University, 722 West 168th St, New York, NY, USA

${ }^{3}$ Herbert Irving Comprehensive Cancer Center, Columbia University Medical Center, 161 Fort Washington Ave., New York, NY, USA

Full list of author information is available at the end of the article
}

$80 \%$ of subjects reported using CAM [3-5], and many reported using more than one modality $[4,6-8]$.

Despite high CAM use among breast cancer patients, research of its safety and effects on breast cancer outcomes is lacking, partly due to methodology limitations. Prior observational studies of breast cancer patients have operationalized CAM use as a single dichotomous variable [9], as individual practices or products $[4,5,8,10,11]$, or employed broad domains of CAM $[6,12,13]$ as defined by the National Center for Complementary and Alternative Medicine [1] and others. Using data from the 2002 National Health Interview Survey, Ayers and Kronenfeld conducted a factor analysis of CAM utilization to highlight 
categories of CAM based on actual use patterns [14]. However, the patterns identified in this population-based sample, in which the prevalence of CAM was relatively low and few subjects used more than one modality [15] may not be applicable to breast cancer survivors.

Although commonly employed in observational research, the analysis of broad CAM domains has been criticized for limiting description of specific products/ techniques $[13,16]$, concealing differences among therapies that could be related to outcomes. Conversely, in studies that analyze the individual effects of a large number of individual practices, chance findings are likely, and teasing out relevant associations may be limited by interactions among modalities [3, 4, 7]. An additional limitation of previous CAM research is the lack of consideration of duration/frequency of treatment, an aspect of CAM behavior that is particularly relevant to causal inference regarding cancer outcomes [17].

Latent class analysis (LCA) is an increasingly popular statistical modeling technique used to uncover heterogeneity in response patterns or clinical characteristics within a population. Its use is common in the social and behavioral sciences and unlike factor analysis, which groups correlated response items, LCA is a personcentered approach [18]. Grouping individuals based on similar patterns of CAM use may address several methodological concerns and provides a practical alternative to traditional subgroup analysis to explore interactions among modalities [19].

Here we present an exploratory latent class analysis of CAM use among breast cancer patients who participated in the Long Island Breast Cancer Study Project [20]. We aim to illustrate the utility of LCA in CAM research, and to explore demographic, clinical and behavioral predictors of different CAM user profiles.

\section{Methods \\ Overview}

Data for this study were obtained from the Long Island Breast Cancer Study Project, a federally mandated casecontrol study to investigate the high incidence of breast cancer in Nassau and Suffolk counties on Long Island, New York [20]. Cases were identified and interviewed shortly after diagnosis in 1996-1997 and, as part of a continuing prospective follow-up study, a second interview among cases was conducted in 2002-2003, which included a questionnaire assessing CAM use. This study was approved by the institutional review boards of Columbia University Medical Center, University of North Carolina, and other collaborating institutions.

\section{Study population}

Female residents of Nassau and Suffolk counties, New York, newly diagnosed with a first primary in situ or invasive breast cancer were identified through a rapid reporting system between August 1996 and July 1997, as previously described [20]. Physician consent was obtained for 1837 cases, 1508 women $(82.1 \%)$ completed the baseline questionnaire, and 1414 agreed to subsequent contact. The follow-up interview was conducted with cases or their proxies during 2002 and 2003 [21]. Only data from the 764 patients who personally completed the full follow-up questionnaire were analyzed in this study. Non-responders to the full follow-up questionnaire were on average older, had less education and lower household incomes, were less likely to be non-Hispanic white, more likely to have invasive disease, and less likely to have had a recent mammogram, than responders, as previously reported [10]. In the current sample, $94 \%$ of participants were nonHispanic and white, and $82 \%$ had invasive (vs in situ) breast cancer [10].

\section{Data collection}

The baseline interview, conducted by trained interviewers roughly three months after diagnosis (mean 96 days), included information on demographics, lifestyle, and breast cancer risk factors. The follow-up interview included questions about the first course of treatment for the first primary breast cancer, and CAM use before and after diagnosis and during treatment. Signed medical records release forms were obtained from case women to abstract data relating to tumor characteristics and treatment during the baseline and follow-up interviews. Informed consent was obtained from all participants before each interview.

\section{CAM Use assessment}

The CAM section of the follow-up questionnaire included detailed questions about 194 modalities in 7 domains that were developed after a review of the literature: 1) vitamin/ mineral supplements; 2) herbs/botanicals; 3) non-vitamin/ mineral non-herbal over-the-counter (OTC) health products; 4) mind-body medicine techniques; 5) special treatments (including biofeedback, colon cleansing and others); 6) diet change; and 7) practitioner-based therapies. After an affirmative response to ever use of a particular product, participants were asked specifically about the time following diagnosis through the question, "How many total years have you taken this product since diagnosis?" Frequency of using each endorsed modality during treatment for breast cancer was then assessed at the day, week or month level. Although some studies have included prayer as a CAM modality, we excluded it because a high proportion of participants reported using it and because a separate study had shown that prayer fit into a latent construct different from mind-body medicine techniques [14]. We also excluded special treatments such as biofeedback, colon 
cleansing, and bioelectromagnetic-based therapy due to very low prevalence of use (1.2\%).

We computed a "cumulative dose index" of each CAM therapy by multiplying the reported number of years used since diagnosis by the reported number of times used per week or month. The cumulative dose index value for vitamins/mineral supplements, herbs, and over-the-counter health products was the number of times taken per day multiplied by years taken; the value computed for mind-body practices and CAM practitioners was the number of times used per month multiplied by number of years used; the value for diet was the number of years used since diagnosis.

\section{Assessment of covariates}

Covariates assessed by questionnaire at baseline included age at diagnosis, education, annual household income, marriage history, religion, and race/ethnicity. Known breast cancer risk factors assessed include use of hormone replacement therapy or oral contraceptives, and any first degree family history of breast cancer. Medical history and mammography were also assessed at baseline, in addition to physical activity between menarche and diagnosis, fruit and vegetable intake assessed through a modified Block food frequency questionnaire, life course alcohol use and cigarette smoking history. An unweighted comorbidity index adapted from the Charlson Comorbidity Index [22] was created. An affirmative response at the baseline interview to a history of each of the following conditions contributed 1 point to the index: diabetes, asthma, myocardial infarction, stroke, gallbladder disease, and previous cancer $(0,1,2$ or more). At the follow-up interview, information was collected on weight and height at diagnosis to estimate body mass index $\left(B M I=\mathrm{kg} / \mathrm{m}^{2}\right)$, as well as the first course of treatment (chemotherapy/radiation/hormone therapy) for the first primary breast cancer.

Medical records were abstracted at baseline and again at follow-up to ascertain information on tumor staging (in situ vs. invasive), tumor estrogen/progesterone receptor (ER/PR) status, and first course of treatment for the first primary breast cancer. Concordance between the treatment data collected by interview and from medical records was exceptionally high (kappa $>90 \%$ ) [21], and thus the information assessed by interview is used here.

\section{Statistical analysis}

The analysis included the 23 modalities used since diagnosis at any dose by at least $10 \%$ of women. Modalities used by fewer than $10 \%$ of women were aggregated into six composite variables according to specified CAM domains. Further, in order to increase the precision of the latent class analysis, factor analysis was performed as a data reduction technique prior to conducting the LCA. A two-step process was used for the factor analysis. Because factor analysis of skewed dichotomous data using Pearson correlation coefficients has been shown to underestimate factor loadings [23], we first computed tetrachoric correlations between dichotomous CAM variables [24]. We then conducted the factor analysis on the tetrachoric correlation matrix using principal axis factoring extraction with oblique factor rotation, and determined the number of factors to be retained using the scree test [25]. Modalities that loaded on a single factor with a factor loading of 0.3 or higher on common factors were grouped together. Each CAM grouping generated through factor analysis represented a subset of modalities with correlated use. The cumulative dose of each grouping was calculated by summing the cumulative dose of all modalities making up the respective grouping. Those not loading on any single factor were retained as separate modalities for use in the LCA.

The summed cumulative dose index for each individual modality or CAM grouping was then categorized into three levels with a cutoff at the median dose among those reporting any use: (1) no use since diagnosis; (2) use since diagnosis at a cumulative dose below the median; and (3) use since diagnosis at a cumulative dose above the median. Latent class analysis was performed with SAS PROC LCA [26] using the consolidated 3-level CAM grouping variables. Models specified to contain one through ten latent classes were evaluated based on Akaike's Information Criterion (AIC), Bayesian Information Criterion (BIC), and the sample-size adjusted BIC. We also considered the reproducibility of the model, as defined by the percentage of iterations yielding the optimal fit, as well as interpretability of the latent classes, when determining the number of latent classes [27].

Using Bayes' theorem, SAS PROC LCA computes each individual's posterior probability of membership in each latent class. Subsequent to determining the best fitting number of classes, participants were assigned to classes based on maximum posterior probability. Bivariate associations of demographic, clinical and behavior variables with assigned latent class were examined using Pearson's chi-squared tests or analysis of variance (ANOVA) for categorical and continuous variables, respectively. Analyses were performed with SAS v.9.3 (SAS Institute Inc., Cary, NC) using two-sided significance tests.

\section{Results}

Between diagnosis and the follow-up interview, study participants reported using CAM practices from a median of 2 domains (range: 0-7) (Table 1). The proportion of women using each individual modality during treatment for their first primary breast cancer has been previously reported [28]. 
Table 1 Prevalence of using multiple domains of complementary and alternative medicine (CAM) since breast cancer diagnosis ${ }^{a}$

\begin{tabular}{llc}
\hline Number of CAM domains used $^{\text {b }}$ & $\mathrm{n}$ & Percent \\
\hline 0 & 38 & 5.0 \\
1 & 181 & 23.7 \\
2 & 184 & 24.1 \\
3 & 138 & 18.1 \\
4 & 114 & 14.9 \\
5 or more & 109 & 14.3 \\
\hline
\end{tabular}

${ }^{a}$ Among Women Diagnosed With Breast Cancer During 1997-1998 Who Completed the Follow-Up Interview in 2002-2003, Long Island, New York ${ }^{\mathrm{b} D}$ Domains include vitamin/mineral supplements, botanical supplements, other natural products, mind-body techniques, special treatments, dietary change, and practitioner-based complementary and alternative medicine treatments

\section{Latent class indicators}

Preliminary factor analysis identified a 3-factor solution, suggesting that most modalities within domains tended to be correlated in practice. However, Echinacea, green tea, massage, and chiropractic failed to load on any single factor (data not shown). Variables reflecting cumulative dose of each CAM grouping identified, in addition to these 4 individual modalities, were used in the latent class analysis (total of 10 possible modalities). The cumulative dose among those reporting use, as well as the probability of using each modality at a high and low cumulative dose, is reported in Table 2.

\section{Identification and interpretation of latent classes}

The primary goal of model selection was to maximize the number of informative classes while maintaining a balance between parsimony and stability of the models. The 5-class model, with the lowest AIC value, was not sufficiently stable; only $36 \%$ of iterations were associated with the best fitting model. According to the BIC and sample-size adjusted BIC, the 2- and 4-class models, respectively, were preferable (Table 3). After careful examination, we selected the four-class model based on the strong repeatability and interpretability of the model.

The latent class with highest membership probability (39.6\%) was termed "low-dose supplement users" due to their low probability of using all CAM modalities relative to the overall sample. Despite very low CAM use by this class, vitamin/mineral supplement use carried a 59 and $19 \%$ estimated probability of use at a low-dose and high-dose, respectively (Table 4). The second largest class (39.3\%), termed "vitamin/mineral supplement users," was distinguished by near-universal use of vitamins and minerals, largely in excess of the median cumulative dose, and above average probability of using green tea and diet change. The third largest class, denoted "mind-body medicine users," (11.9 \%) was characterized by near-ubiquitous use of mind-body medicine techniques and massage, predominantly below the median use frequency, and less common use of several other types of CAM. The smallest class, called "multi-

Table 2 Use prevalence of commonly-used individual CAM modalities and CAM groupings, Long Island, New York $(n=764)^{\mathrm{a}}$

\begin{tabular}{|c|c|c|c|c|}
\hline & No use & Low dose & High dose & Median (IQR) cumulative dose $\mathrm{e}^{\mathrm{b}}$ \\
\hline Vitamin/mineral supplements $^{c}$ & $11 \%$ & $45 \%$ & $45 \%$ & $7.7(2.0-19.0)$ \\
\hline Echinacea & $86 \%$ & $8 \%$ & $6 \%$ & $0.4(0.1-0.6)$ \\
\hline Green tea & $77 \%$ & $15 \%$ & $8 \%$ & $0.6(0.1-1.3)$ \\
\hline Other herbs $^{d}$ & $79 \%$ & $11 \%$ & $10 \%$ & $1.0(0.4-4.5)$ \\
\hline Natural products ${ }^{\mathrm{e}}$ & $78 \%$ & $11 \%$ & $11 \%$ & $1.0(0.4-4.6)$ \\
\hline Mind-body techniques ${ }^{f}$ & $59 \%$ & $20 \%$ & $20 \%$ & $19.3(4.5-135.0)$ \\
\hline Diet change $\mathrm{e}^{\mathrm{g}}$ & $67 \%$ & $18 \%$ & $15 \%$ & $7.0(4.5-12.0)$ \\
\hline Massage & $83 \%$ & $13 \%$ & $4 \%$ & $4.5(2.0-4.5)$ \\
\hline Chiropractic & $82 \%$ & $9 \%$ & $9 \%$ & $3.3(1.0-9.0)$ \\
\hline Other practitioner-based CAM ${ }^{h}$ & $88 \%$ & $7 \%$ & $5 \%$ & $2.0(1.0-3.5)$ \\
\hline
\end{tabular}

Abbreviations: CAM complementary and alternative medicine, $I Q R$ interquartile range

andicator variables were determined through factor analysis; CAM groupings represent clusters of individual modalities that tended to be practiced together; cumulative dose for groupings was computed by summing cumulative doses of contributing modalities

${ }^{b}$ Cumulative dose since diagnosis for vitamin/mineral supplements, echinacea, green tea, other herbs, and natural products, expressed as number of times taken per day multiplied by years taken; for mind-body techniques, massage, chiropractic, and practitioner-based CAM, as number of times used per month times number of years taken; and for diet, as the number of combined years since diagnosis

${ }^{\complement}$ Vitamin/mineral supplements includes all nutritional supplements that include multiple and single vitamins/minerals

${ }^{\mathrm{d}}$ Other herbs includes all herbs and botanicals in pill, tea, extract, infusion, oil, powder, or cream form, with exception of echinacea and green tea

e Natural product includes all non-herbal, non-vitamin over-the-counter CAM products, predominantly glucosamine, fish oil, coenzyme Q10, flax seed oil, and acidophilus

fMind-body techniques includes support groups; psychotherapy with social worker, psychologist, or psychiatrist; meditation; vizualization/imagery; hypnosis; Reiki, healing touch or other energy therapy; tai chi; qi gong; yoga; dance therapy; art therapy; music therapy; and poetry therapy or journaling

${ }^{9}$ Diet changes considered were vegan/vegetarian; no red meat but do eat chcken and/or fish; organic fruits and vegetables; macrobiotic diet; low-fat diet; high fiber diet; change consumption of soy products; diet or program designed to lose weight

${ }^{\mathrm{h}}$ Other practitioner-based CAM includes acupuncture, ayurvedic medicine, traditional Chinese medicine, herbalist, homeopathy, Native American medicine, naturopathic physician, nutritionist/dietician, tibetan medicine, or other practitioner based CAM treatments 
Table 3 Model fit statistics for estimating classes of CAM users through latent class analysis

\begin{tabular}{llllll}
\hline $\begin{array}{l}\text { Number } \\
\text { of classes }\end{array}$ & $\begin{array}{l}\text { Likelihood } \\
\text { ratio G2 }\end{array}$ & AIC & BIC & $\begin{array}{l}\text { Sample size } \\
\text { Adjusted BIC }\end{array}$ & $\begin{array}{l}\text { \% of seeds } \\
\text { associated } \\
\text { with best fit }\end{array}$ \\
\hline 1 & 2903.8 & 2943.8 & 3036.5 & 2973.0 & $100 \%$ \\
2 & 2313.5 & 2395.5 & 2585.7 & 2455.5 & $100 \%$ \\
3 & 2202.8 & 2326.8 & 2614.4 & 2417.5 & $40 \%$ \\
$4^{\text {a }}$ & 2117.9 & 2283.9 & 2668.9 & 2405.3 & $100 \%$ \\
5 & 2070.4 & 2278.4 & 2760.8 & 2430.6 & $36 \%$ \\
6 & 2028.9 & 2278.9 & 2858.7 & 2461.8 & $13 \%$ \\
7 & 1992.5 & 2284.5 & 2961.7 & 2498.1 & $3 \%$
\end{tabular}

Abbreviations: AIC Akaike Information Criterion, BIC Bayesian Information Criterion, CAM complementary and alternative medicine

aselected model contained 4 latent classes

modality high-dose users" (9.1\%) was characterized by a relatively high probability of using nearly all CAM modalities. Probabilities of CAM use conditional on latent class membership are shown graphically in Fig. 1.

\section{Predictors of latent class membership}

Participants were classified into latent classes corresponding to their highest posterior probability, as derived from the LCA. The mean maximum posterior probability was 0.83 , ranging from 0.82 to 0.85 across classes, suggesting low classification error (data not shown). Predictors of membership in the vitamin/mineral supplement users, mind-body medicine users and multi-modality high-doseusers classes were similar, when compared with those of the low-dose supplement users (Table 5 and Table 6). Predictors of membership in classes characterized by substantial CAM use included younger age, more education, higher income, Jewish religion, ideal body mass index, higher intake of fruits and vegetables, higher levels of physical activity, receipt of adjuvant chemotherapy, and prior use of oral contraceptives.

\section{Discussion}

We identified four distinct classes of CAM users through a latent class analysis of breast cancer survivors with near-universal use of complementary and alternative medicine. Because much of that use involved vita$\mathrm{min} /$ mineral supplements, we termed as low-dose supplement users patients who were likely to report using common vitamin/mineral supplements but not other CAM since diagnosis. Latent classes were characterized by varying probabilities of using CAM products and techniques in particular groupings.

Results of previous studies suggest that breast cancer patients have a higher probability and more varied CAM use than the general population. While estimates from the 2002 National Health Interview Survey suggest that those in the general population rarely use more than one form of CAM [15], CAM use among breast cancer patients usually involves multiple modalities $[4,6,7]$. Our results are consistent with this observation. Previous studies of breast cancer patients have shown that younger age, higher education and income levels, and receipt of chemotherapy are associated with CAM use in breast cancer patients and survivors [4, 6, 11, 12, 29]. Multi-modality high-dose users and mind-body medicine users are those with a high probability of using modalities generally included in more conservative definitions of CAM use, namely mind-body medicine practices, practitioner-based treatments, and plant-based remedies [29]. Compared with membership in the lowdose supplement users class, membership in the other

Table 4 Use of CAM modalities since breast cancer diagnosis, conditional on latent class membership ${ }^{a}$

\begin{tabular}{|c|c|c|c|c|c|c|c|c|}
\hline & \multicolumn{2}{|c|}{$\begin{array}{l}\text { Low-dose supplement } \\
\text { users (39.6\%) }\end{array}$} & \multicolumn{2}{|c|}{$\begin{array}{l}\text { Vitamin/mineral supplement } \\
\text { users }(39.3 \%)\end{array}$} & \multicolumn{2}{|c|}{$\begin{array}{l}\text { Mind-body medicine users } \\
(11.9 \%)\end{array}$} & \multicolumn{2}{|c|}{$\begin{array}{l}\text { Multi-modality high-dose } \\
\text { users (9.1\%) }\end{array}$} \\
\hline & Low dose & High dose & Low dose & High dose & Low dose & High dose & Low dose & High dose \\
\hline Vitamin/mineral supplements & 0.59 & 0.19 & 0.34 & 0.63 & 0.52 & 0.41 & 0.19 & 0.81 \\
\hline Echinacea & 0.00 & 0.00 & 0.11 & 0.07 & 0.17 & 0.05 & 0.19 & 0.30 \\
\hline Green tea & 0.02 & 0.00 & 0.22 & 0.13 & 0.22 & 0.01 & 0.30 & 0.33 \\
\hline Other herbs & 0.02 & 0.00 & 0.15 & 0.11 & 0.24 & 0.04 & 0.16 & 0.55 \\
\hline Natural products & 0.03 & 0.01 & 0.15 & 0.13 & 0.28 & 0.00 & 0.11 & 0.58 \\
\hline Mind-body techniques & 0.07 & 0.08 & 0.18 & 0.19 & 0.66 & 0.33 & 0.29 & 0.62 \\
\hline Diet change & 0.16 & 0.02 & 0.22 & 0.17 & 0.15 & 0.19 & 0.12 & 0.54 \\
\hline Massage & 0.02 & 0.00 & 0.03 & 0.02 & 0.60 & 0.13 & 0.37 & 0.18 \\
\hline Chiropractic & 0.04 & 0.04 & 0.12 & 0.08 & 0.14 & 0.11 & 0.13 & 0.33 \\
\hline Other practitioner-based CAM & 0.01 & 0.00 & 0.08 & 0.04 & 0.08 & 0.10 & 0.28 & 0.26 \\
\hline
\end{tabular}

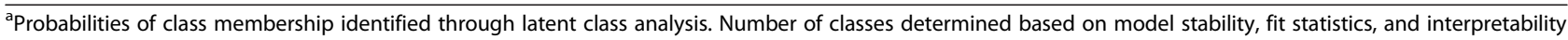
of latent classes

Abbreviation: CAM, complementary and alternative medicine 


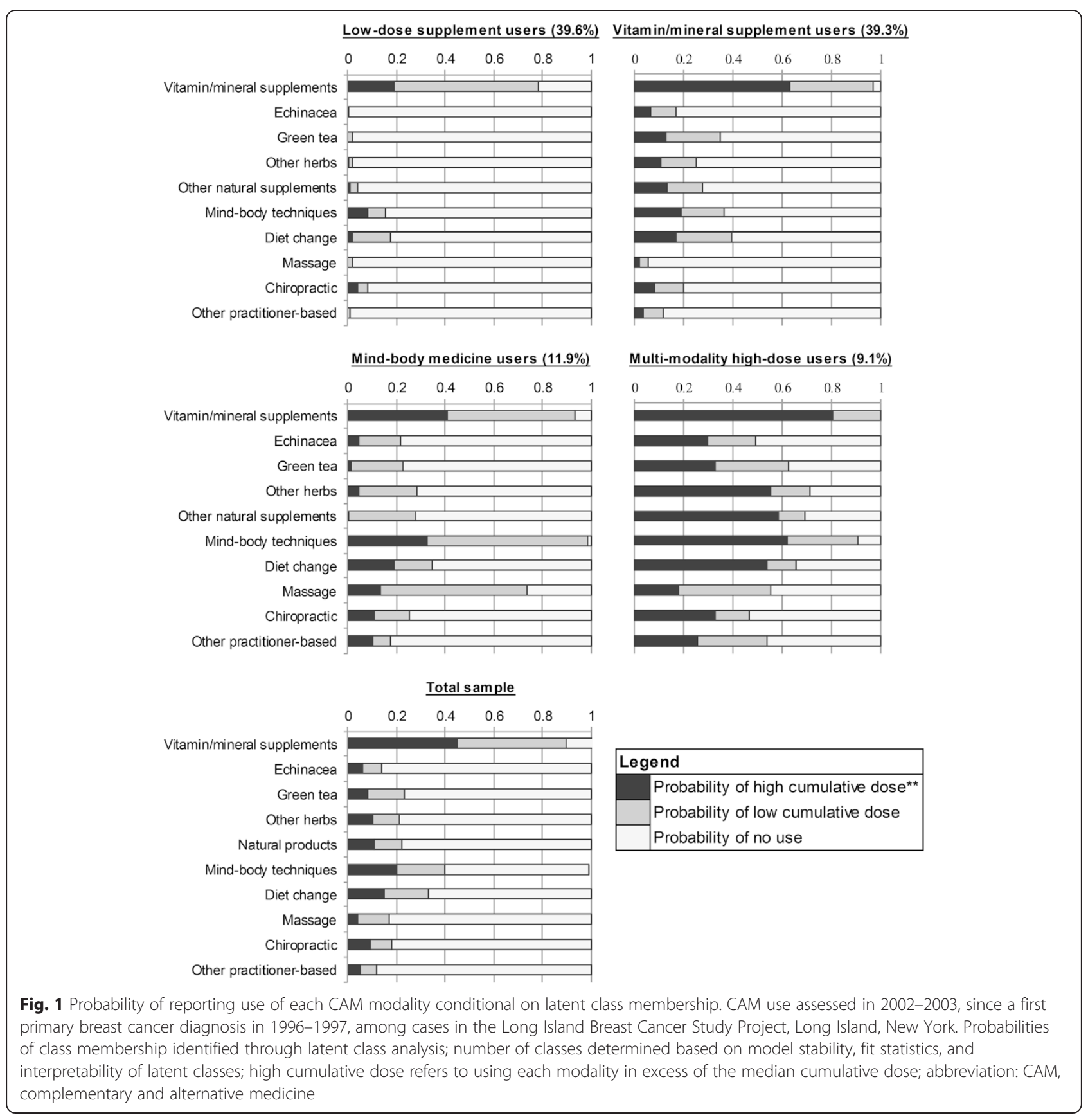

classes was strongly predicted by known correlates of CAM use, lending credibility to our analytic approach.

To our knowledge only one prior study has assessed CAM use patterns in cancer patients or survivors at the individual level. A cluster analysis conducted by Hok and colleagues in 38 cancer patients characterized CAM users by their therapeutic preferences [7]. Four types of CAM users emerged from their analysis, characterized by the number of NCCAM domains used and a preference for either energy therapies or alternative medical systems and treatment centers. This differs from the present study conducted among a population-based sample of 764 breast cancer survivors in which the most important modalities for discriminating classes were mind-body techniques and massage. This discrepancy is likely explained by differences in the selection of participants, with the small previous study focused on patients with a high commitment to CAM use, with pervasive use of biological-based and mind-body CAM modalities.

Ours is the first study of CAM in breast cancer patients to take into account a measure of relative 
Table 5 Demographics and breast cancer risk factors by latent class of CAM use $(n=764)^{a, b}$

\begin{tabular}{|c|c|c|c|c|c|c|c|c|c|c|}
\hline & \multicolumn{2}{|c|}{$\begin{array}{l}\text { Total } \\
\text { sample }\end{array}$} & \multicolumn{2}{|c|}{$\begin{array}{l}\text { Low-dose } \\
\text { supplement users }\end{array}$} & \multicolumn{2}{|c|}{$\begin{array}{l}\text { Vitamin/mineral } \\
\text { supplement users }\end{array}$} & \multicolumn{2}{|c|}{$\begin{array}{l}\text { Mind-body } \\
\text { medicine users }\end{array}$} & \multicolumn{2}{|c|}{$\begin{array}{l}\text { Multi-modality high } \\
\text { dose users }\end{array}$} \\
\hline & $\bar{n}$ & $\%^{\mathrm{e}}$ & $\bar{n}$ & $\%^{\mathrm{e}}$ & $\bar{n}$ & $\%^{\mathrm{e}}$ & $\bar{n}$ & $\%^{\mathrm{e}}$ & $\bar{n}$ & $\%^{\mathrm{e}}$ \\
\hline \multicolumn{11}{|l|}{ Demographics } \\
\hline Age in years, mean $(S D)^{d}$ & 56.3 & $(11.4)$ & 58.8 & $(12.0)$ & 55.6 & $(10.5)$ & 50.9 & $(9.8)$ & 53.1 & $(10.0)$ \\
\hline \multicolumn{11}{|l|}{ Age at diagnosis ${ }^{d}$} \\
\hline$<45$ years & 136 & 17.8 & 48 & 14.3 & 51 & 18.3 & 24 & 28.6 & 13 & 19.7 \\
\hline $45-54$ years & 231 & 30.2 & 84 & 25.1 & 88 & 31.5 & 34 & 40.5 & 25 & 37.9 \\
\hline $55-64$ years & 204 & 26.7 & 85 & 25.4 & 81 & 29.0 & 18 & 21.4 & 20 & 30.3 \\
\hline $65+$ years & 193 & 25.3 & 118 & 35.2 & 59 & 21.2 & 8 & 9.5 & 8 & 12.1 \\
\hline \multicolumn{11}{|l|}{ Religion ${ }^{c}$} \\
\hline Protestant & 173 & 22.6 & 82 & 24.5 & 65 & 23.3 & 13 & 15.5 & 13 & 19.7 \\
\hline Catholic & 424 & 55.5 & 198 & 59.1 & 151 & 54.1 & 43 & 51.2 & 32 & 48.5 \\
\hline Jewish & 153 & 20.0 & 49 & 14.6 & 58 & 20.8 & 27 & 32.1 & 19 & 28.8 \\
\hline Other/refused & 14 & 1.8 & 6 & 1.8 & 5 & 1.8 & $f$ & $f$ & $f$ & $f$ \\
\hline \multicolumn{11}{|l|}{ Annual household income ${ }^{d}$} \\
\hline Less than $\$ 25,000$ & 79 & 10.3 & 50 & 14.9 & 18 & 6.5 & f & f & 7 & 10.6 \\
\hline$\$ 25,000-\$ 49,999$ & 234 & 30.6 & 127 & 37.9 & 81 & 29.0 & 13 & 15.5 & 13 & 19.7 \\
\hline$\$ 50,000-\$ 89,999$ & 266 & 34.8 & 100 & 29.9 & 94 & 33.7 & 44 & 52.4 & 28 & 42.4 \\
\hline Greater than $\$ 90,000$ & 185 & 24.2 & 58 & 17.3 & 86 & 30.8 & 23 & 27.4 & 18 & 27.3 \\
\hline \multicolumn{11}{|l|}{ Education $^{d}$} \\
\hline High school graduate or less & 301 & 39.4 & 185 & 55.2 & 92 & 33.0 & 10 & 11.9 & 14 & 21.2 \\
\hline Some college & 195 & 25.5 & 77 & 23.0 & 72 & 25.8 & 28 & 33.3 & 18 & 27.3 \\
\hline College graduate & 111 & 14.5 & 31 & 9.3 & 56 & 20.1 & 16 & 19.1 & 8 & 12.1 \\
\hline Postgraduate & 157 & 20.6 & 42 & 12.5 & 59 & 21.2 & 30 & 35.7 & 26 & 39.4 \\
\hline \multicolumn{11}{|l|}{ Breast cancer risk factors } \\
\hline \multicolumn{11}{|l|}{ First degree family history of $B C$} \\
\hline No & 595 & 77.9 & 256 & 76.4 & 217 & 77.8 & 65 & 77.4 & 57 & 86.4 \\
\hline Yes & 151 & 19.8 & 66 & 19.7 & 59 & 21.2 & 19 & 22.6 & 7 & 10.6 \\
\hline \multicolumn{11}{|l|}{ Prior oral contraceptive use ${ }^{d}$} \\
\hline Never & 376 & 49.2 & 190 & 56.7 & 135 & 48.4 & 25 & 29.8 & 26 & 39.4 \\
\hline Ever & 386 & 50.5 & 144 & 43.0 & 143 & 51.3 & 59 & 70.2 & 40 & 60.6 \\
\hline \multicolumn{11}{|c|}{ Prior hormone replacement therapy use } \\
\hline Never & 511 & 66.9 & 236 & 70.5 & 187 & 67.0 & 52 & 61.9 & 36 & 54.6 \\
\hline Ever & 253 & 33.1 & 99 & 29.6 & 92 & 33.0 & 32 & 38.1 & 30 & 45.5 \\
\hline
\end{tabular}


Table 5 Demographics and breast cancer risk factors by latent class of CAM use $(n=764)^{\mathrm{a}, \mathrm{b}}$ (Continued)

\begin{tabular}{|c|c|c|c|c|c|c|c|c|c|c|}
\hline \multicolumn{11}{|c|}{ Menopausal status at diagnosis $^{d}$} \\
\hline Pre-menopausal & 279 & 36.5 & 87 & 26.0 & 117 & 41.9 & 45 & 53.6 & 30 & 45.5 \\
\hline Post-menopausal & 465 & 60.9 & 239 & 71.3 & 158 & 56.6 & 38 & 45.2 & 30 & 45.5 \\
\hline \multicolumn{11}{|l|}{ BMl at diagnosis $^{\mathrm{d}}$} \\
\hline$<25$ & 375 & 49.1 & 139 & 41.5 & 158 & 56.6 & 36 & 42.9 & 42 & 63.6 \\
\hline $25-29$ & 241 & 31.5 & 113 & 33.7 & 86 & 30.8 & 27 & 32.1 & 15 & 22.7 \\
\hline $30+$ & 143 & 18.7 & 80 & 23.9 & 34 & 12.2 & 20 & 23.8 & 9 & 13.6 \\
\hline
\end{tabular}

Abbreviations: $B C$ breast cancer, $B M I$ body mass index, $C A M$ complementary and alternative medicine, $S D$ standard deviation

a Participants assigned to class based on highest posterior class membership probability, as determined through SAS PROC LCA

${ }^{\mathrm{b}} \mathrm{P}$-values based on Pearson chi-squared tests or analysis of variance (ANOVA)

${ }^{\mathrm{C}} \mathrm{P}<0.05$

${ }^{\mathrm{d}} \mathrm{P}<0.001$

${ }^{\text {e}}$ Column percentages may not add up to 100 due to missing data

fValues not displayed due to cell sizes $<5$

Table 6 Health behaviors and clinical characteristics by latent class of CAM use $(n=764)^{a, b}$

\begin{tabular}{|c|c|c|c|c|c|c|c|c|c|c|}
\hline & \multicolumn{2}{|c|}{$\begin{array}{l}\text { Total } \\
\text { sample }\end{array}$} & \multicolumn{2}{|c|}{$\begin{array}{l}\text { Low-dose } \\
\text { supplement users }\end{array}$} & \multicolumn{2}{|c|}{$\begin{array}{l}\text { Vitamin/mineral } \\
\text { supplement users }\end{array}$} & \multicolumn{2}{|c|}{$\begin{array}{l}\text { Mind-body } \\
\text { medicine users }\end{array}$} & \multicolumn{2}{|c|}{$\begin{array}{l}\text { Multi-modality } \\
\text { high-dose users }\end{array}$} \\
\hline & $n$ & $\%^{\mathrm{e}}$ & $n$ & $\%^{e}$ & $n$ & $\%^{\mathrm{e}}$ & $n$ & $\%^{e}$ & $n$ & $\%^{\mathrm{e}}$ \\
\hline \multicolumn{11}{|l|}{ Health behaviors } \\
\hline \multicolumn{11}{|l|}{ Mammogram } \\
\hline No mammogram in last 5 years & 32 & 4.2 & 19 & 5.7 & 8 & 2.9 & f & f & $f$ & f \\
\hline Had mammogram $<5$ years ago & 721 & 94.4 & 309 & 92.2 & 268 & 96.1 & 80 & 95.2 & 64 & 97.0 \\
\hline \multicolumn{11}{|l|}{ Cigarette smoking status $^{c}$} \\
\hline Never & 337 & 44.1 & 137 & 40.9 & 130 & 46.6 & 46 & 54.8 & 24 & 36.4 \\
\hline Current & 142 & 18.6 & 70 & 20.9 & 56 & 20.1 & 6 & 7.1 & 10 & 15.2 \\
\hline Former & 285 & 37.3 & 128 & 38.2 & 93 & 33.3 & 32 & 38.1 & 32 & 48.5 \\
\hline \multicolumn{11}{|l|}{ Alcohol use } \\
\hline Never & 258 & 33.8 & 120 & 35.8 & 86 & 30.8 & 32 & 38.1 & 20 & 30.3 \\
\hline Ever & 506 & 66.2 & 215 & 64.2 & 193 & 69.2 & 52 & 61.9 & 46 & 69.7 \\
\hline \multicolumn{11}{|l|}{ Physical activity since menarche ${ }^{d}$} \\
\hline None & 185 & 24.2 & 110 & 32.8 & 51 & 18.3 & 18 & 21.4 & 6 & 9.1 \\
\hline 0-0.69 h/week & 172 & 22.5 & 77 & 23.0 & 57 & 20.4 & 23 & 27.4 & 15 & 22.7 \\
\hline $0.70-2.6 \mathrm{~h} /$ week & 184 & 24.1 & 81 & 24.2 & 70 & 25.1 & 13 & 15.5 & 20 & 30.3 \\
\hline$\geq 2.7 \mathrm{~h} /$ week & 181 & 23.7 & 52 & 15.5 & 81 & 29.0 & 28 & 33.3 & 20 & 30.3 \\
\hline \multicolumn{11}{|l|}{ Fruit and vegetable intake ${ }^{d}$} \\
\hline 0-34 servings per week & 475 & 62.2 & 238 & 71.0 & 159 & 57.0 & 42 & 50.0 & 36 & 54.6 \\
\hline$\geq 35$ servings per week & 281 & 36.8 & 95 & 28.4 & 116 & 41.6 & 40 & 47.6 & 30 & 45.5 \\
\hline \multicolumn{11}{|l|}{ Clinical characteristics } \\
\hline \multicolumn{11}{|l|}{ Stage at diagnosis for first primary } \\
\hline In situ & 137 & 17.9 & 52 & 15.5 & 48 & 17.2 & 23 & 27.4 & 14 & 21.2 \\
\hline Invasive & 627 & 82.1 & 283 & 84.5 & 231 & 82.8 & 61 & 72.6 & 52 & 78.8 \\
\hline \multicolumn{11}{|c|}{ Hormone receptor status for first primary $B C$} \\
\hline ER- / PR- & 99 & 13.0 & 43 & 12.8 & 37 & 13.3 & 35 & 41.7 & 5 & 7.6 \\
\hline ER- / PR+ & 27 & 3.5 & 11 & 3.3 & 14 & 5.0 & 14 & 16.7 & f & f \\
\hline
\end{tabular}


Table 6 Health behaviors and clinical characteristics by latent class of CAM use $(n=764)^{\mathrm{a}, \mathrm{b}}$ (Continued)

\begin{tabular}{|c|c|c|c|c|c|c|c|c|c|c|}
\hline $\mathrm{ER}+/ \mathrm{PR}-$ & 57 & 7.5 & 31 & 9.3 & 19 & 6.8 & $f$ & $\bar{f}$ & $f$ & $f$ \\
\hline $\mathrm{ER}+/ \mathrm{PR}+$ & 292 & 38.2 & 135 & 40.3 & 101 & 36.2 & 32 & 38.1 & 24 & 36.4 \\
\hline \multicolumn{11}{|c|}{ First course treatment received for first primary $B C$} \\
\hline Chemotherapy $^{c}$ & 310 & 40.6 & 117 & 34.9 & 123 & 44.1 & 40 & 47.6 & 30 & 45.5 \\
\hline Radiation & 464 & 60.7 & 206 & 61.5 & 180 & 64.5 & 42 & 50.0 & 36 & 54.6 \\
\hline Hormonal therapy ${ }^{c}$ & 462 & 60.5 & 207 & 61.8 & 177 & 63.4 & 39 & 46.4 & 39 & 59.1 \\
\hline \multicolumn{11}{|c|}{ Serious comorbidities at diagnosis } \\
\hline None & 463 & 60.6 & 194 & 57.9 & 180 & 64.5 & 49 & 58.3 & 40 & 60.6 \\
\hline One & 218 & 28.5 & 101 & 30.2 & 74 & 26.5 & 25 & 29.8 & 18 & 27.3 \\
\hline Two or more & 83 & 10.9 & 40 & 11.9 & 25 & 9.0 & 10 & 11.9 & 8 & 12.1 \\
\hline
\end{tabular}

Abbreviations: $B C$ breast cancer, $B M I$ body mass index, $C A M$ complementary and alternative medicine

${ }^{\text {a }}$ Participants assigned to class based on highest posterior class membership probability, as determined through SAS PROC LCA

${ }^{b} \mathrm{P}$-values based on Pearson chi-squared tests or analysis of variance (ANOVA)

${ }^{\mathrm{c}} \mathrm{P}<0.05$

${ }^{\mathrm{d}} \mathrm{P}<0.001$

e Column percentages may not add up to 100 due to missing data

${ }^{f}$ Values not displayed due to cell sizes $<5$

cumulative CAM dose. Here, a salient aspect of vitamin/ mineral supplement users was their tendency to use supplements at a higher intensity/duration than low-dose supplement users. We believe differentiating users based on this factor enhances identification of subgroups of breast cancer patients who are often users of multiple CAM modalities, even though incorporating this strategy weakens precision of parameter estimates. Indeed, data sparseness that resulted from pairing this added complexity of the large number of LCA indicator variables with our relatively small sample size necessitated collapsing CAM modalities prior to performing the LCA [30]. Limited sample sizes in future studies may necessitate aggregating CAM practices using factor analysis as done here, or by combining similar treatment modalities, prior to performing the LCA. Additional strengths of this study include the rigorous consideration of covariates and comprehensive CAM assessment.

Because data on frequency of CAM use were available only during active breast cancer treatment, the cumulative dose component of the analysis was calculated by extrapolating the frequency of use during treatment to all time since diagnosis. Bias therefore may have been introduced regarding modalities correlated with conventional treatments. The findings may also reflect selection bias because non-responders differed from participants on several predictors of CAM use [10]. Other limitations include lack of adjustment for multiple comparisons, although consistency with prior studies lends credibility to the results. It is not clear how these findings may be generalized to different regions and more diverse populations, and whether the use patterns identified here are still relevant to more recently diagnosed breast cancer patients on Long Island.

\section{Conclusion}

In conclusion, this analysis of breast cancer patients suggests four subgroups of women characterized by their use of multiple complementary therapies simultaneously. A large proportion $(71.3 \%)$ of study participants reported using two or more forms of CAM following diagnosis and nearly $10 \%$ were committed users of multiple modalities. Latent class analysis was shown to be an effective method for grouping individual breast cancer patients based on multidimensional patterns of CAM use. The generalizability of the latent classes identified here to populations with different socio-demographic and clinical characteristics remains to be determined. However, LCA presents a nuanced approach to data reduction and subgroup analysis in populations with high use of multiple forms of CAM. Further research using LCAderived classes may be especially useful to investigate causal relationships between CAM and cancer outcomes among patients who use more than one CAM modality.

\section{Abbreviations}

AIC: Akaike's information criterion; ANOVA: Analysis of variance; BC: Breast cancer; BIC: Bayesian information criterion; BMI: Body mass index;

CAM: Complementary and alternative medicine; ER: Estrogen receptor; LCA: Latent class analysis; OTC: Over the counter; PR: Progesterone receptor; SD: Standard deviation.

\section{Competing interests}

All authors contributing to this work declare that there exist no potential conflicts of interests, financial or otherwise.

\section{Authors' contributions}

GS devised the analytic strategy, performed the analysis, contributed to interpretation of results, and drafted the manuscript; MDG helped draft the manuscript and interpret the results; HG devised the conceptual framework, assisted with results interpretation, and participated in manuscript preparation; ISJ assisted with results interpretation and manuscript preparation; MW helped devise the analytic strategy, provided statistical expertise, and provided critical revisions to the manuscript; PA, PTB, MBT, ST 
and AN contributed to interpretation of results and provided critical revisions to the manuscript. All authors read and approved the final manuscript.

\section{Acknowledgements}

This work was supported in part by: the National Institutes of Health (grant numbers ES 66572, CA66572, ES10126, and CA141052) and the Livestrong Foundation.

\section{Author details}

${ }^{1}$ Department of Epidemiology, Mailman School of Public Health, Columbia University, 722 West 168th St, New York, NY, USA. ${ }^{2}$ Department of Epidemiology, University of North Carolina, 2101 McGavran-Greenberg Hall, CB \#7435 Chapel Hill, NC, USA. ${ }^{3}$ Herbert Irving Comprehensive Cancer Center, Columbia University Medical Center, 161 Fort Washington Ave., New York, NY, USA. ${ }^{4}$ Department of Biostatistics, Mailman School of Public Health, Columbia University, 722 West 168th St, New York, NY, USA. ${ }^{5}$ Department of Nutrition, University of North Carolina, 2200 McGavran-Greenberg Hall, CB \#7461 Chapel Hill, NC, USA. ${ }^{6}$ Department of Preventive Medicine, Mount Sinai School of Medicine, 17 E 102nd Street, New York, NY, USA ${ }^{7}$ Department of Medicine, College of Physicians and Surgeons, Columbia University, 630 West 168th Street, New York, NY, USA. ${ }^{8}$ Present address: 722 W. 168th St., Room 733, New York, NY 10032, USA.

Received: 7 June 2015 Accepted: 13 November 2015 Published online: 19 November 2015

\section{References}

1. National Center for Complementary and Alternative Medicine. NCCAM third strategic plan: exploring the science of complementary and alternative medicine. Washington, DC: National Center for Complementary and Alternative Medicine; 2011.

2. Harris PE, Cooper KL, Relton C, Thomas KJ. Prevalence of complementary and alternative medicine (CAM) use by the general population: a systematic review and update. Int J Clin Pract. 2012;66:924-39.

3. Yates JS, Mustian KM, Morrow GR, Gillies LJ, Padmanaban D, Atkins JN, et al. Prevalence of complementary and alternative medicine use in cancer patients during treatment. Support Care Cancer. 2005;13:806-11.

4. Greenlee H, Kwan MLM, Ergas IIJ, Sherman KJ, Krathwohl SE, Bonnell C, et al. Complementary and alternative therapy use before and after breast cancer diagnosis: the Pathways Study. Breast Cancer Res. 2009;117:653-65.

5. Boon HS, Olatunde F, Zick SM. Trends in complementary/alternative medicine use by breast cancer survivors: comparing survey data from 1998 and 2005. BMC Womens Health. 2007;7:4.

6. Buettner C, Kroenke CH, Phillips RS, Davis RB, Eisenberg DM, Holmes MD. Correlates of use of different types of complementary and alternative medicine by breast cancer survivors in the nurses' health study. Breast Cancer Res Treat. 2006;100:219-27.

7. Hök J, Tishelman C, Ploner A, Forss A, Falkenberg T. Mapping patterns of complementary and alternative medicine use in cancer: an explorative cross-sectional study of individuals with reported positive "exceptional" experiences. BMC Complement Altern Med. 2008:8:48.

8. Ashikaga T, Bosompra K, O'Brien P, Nelson L. Use of complimentary and alternative medicine by breast cancer patients: prevalence, patterns and communication with physicians. Support Care Cancer. 2002;10:542-8.

9. Carpenter CL, Ganz PA, Bernstein L. Complementary and alternative therapies among very long-term breast cancer survivors. Breast Cancer Res Treat. 2009;116:387-96.

10. Greenlee H, Gammon MD, Abrahamson PE, Gaudet MM, Terry MB, Hershman DL, et al. Prevalence and predictors of antioxidant supplement use during breast cancer treatment: the long island breast cancer study project. Cancer. 2009;115:3271-82

11. Davis SR, Lijovic M, Fradkin P, Bradbury J, La China M, Schwarz M, et al. Use of complementary and alternative therapy by women in the first 2 years after diagnosis and treatment of invasive breast cancer. Menopause. 2010;17:1004-9.
12. Pedersen CG, Christensen S, Jensen AB, Zachariae R. Prevalence, socio-demographic and clinical predictors of post-diagnostic utilisation of different types of complementary and alternative medicine (CAM) in a nationwide cohort of Danish women treated for primary breast cancer. Eur J Cancer. 2009;45:3172-81.

13. Matsuno RK, Pagano IS, Maskarinec G, Issell BF, Gotay CC. Complementary and alternative medicine use and breast cancer prognosis: a pooled analysis of four population-based studies of breast cancer survivors. J Womens Health (Larchmt). 2012;21:1252-8.

14. Ayers SL, Kronenfeld JJ. Using factor analysis to create complementary and alternative medicine domains: an examination of patterns of use. Health (London). 2010;14:234-52.

15. Neiberg RH, Aickin M, Grzywacz JG, Lang W, Quandt S a, Bell R a, Arcury T a: Occurrence and co-occurrence of types of complementary and alternative medicine use by age, gender, ethnicity, and education among adults in the United States: the. National Health Interview Survey (NHIS). J Altern Complement Med. 2002;2011(17):363-70.

16. Astin JA, Reilly C, Perkins C, Child WL. Breast cancer patients' perspectives on and use of complementary and alternative medicine: a study by the Susan G. Komen breast cancer foundation. J Soc Integr Oncol. 2006:4:157-69.

17. Weed DL, Gorelic LS. The practice of causal inference in cancer epidemiology. Cancer Epidemiol Biomarkers Prev. 1996;5:303-11.

18. Lanza ST, Rhoades BL, Nix RL, Greenberg MT. Modeling the interplay of multilevel risk factors for future academic and behavior problems: a person-centered approach. Dev Psychopathol. 2010;22:313-35.

19. Lanza ST, Rhoades BBL. Latent class analysis: an alternative perspective on subgroup analysis in prevention and treatment. Prev Sci. 2013;14:157-68.

20. Gammon MD, Neugut Al, Santella RM, Teitelbaum SL, Britton JA, Terry MB, et al. The long island breast cancer study project: description of a multi-institutional collaboration to identify environmental risk factors for breast cancer. Breast Cancer Res Treat. 2002;74:235-54.

21. Cleveland RJ, Eng SM, Abrahamson PE, Britton JA, Teitelbaum SL, Neugut Al, et al. Weight gain prior to diagnosis and survival from breast cancer. Cancer Epidemiol Biomarkers Prev. 2007;16:1803-11.

22. Charlson M, Pompei P. A new method of classifying prognostic comorbidity in longitudinal studies: development and validation. J chronic. 1987;40:373-83.

23. Schumacker RE, Beyerlein ST. Confirmatory factor analysis with different correlation types and estimation methods. Struct Equ Model. 2000;74:629-36.

24. Fleming JS. TETCORR: a computer program to compute smoothed tetrachoric correlation matrices. Behav Res Methods. 2005;37:59-64.

25. Henson RK. Use of exploratory factor analysis in published research: common errors and some comment on improved practice. Educ Psychol Meas. 2006;66:393-416.

26. Lanza S, Collins L. PROC LCA: A SAS procedure for latent class analysis. Struct Equ. 2007;14(4):671-94.

27. Garrett ES, Zeger SL. Latent class model diagnosis. Biometrics. 2000;56:1055-67.

28. Link AR, Gammon MD, Jacobson JS, Abrahamson P, Bradshaw PT, Terry $M B$, et al. Use of self-care and practitioner-based forms of complementary and alternative medicine before and after a diagnosis of breast cancer. Evid Based Complement Alternat Med. 2013;2013:301549

29. Balneaves LG, Bottorff JL, Hislop TG, Herbert C. Levels of commitment: exploring complementary therapy use by women with breast cancer. J Altern Complement Med. 2006;12:459-66.

30. Wurpts IC, Geiser C. Is adding more indicators to a latent class analysis beneficial or detrimental? Results of a Monte-Carlo study. Front Psychol. 2014;5(August):1-15. 